\title{
No Difference in Physical Activity Associated with Cannabis Use Status in a Nationally Representative Sample of U.S. Adults
}

\author{
Lydia Q. Ong
}

Chapman University

John Bellettiere

University of California San Diego

Citlali Alvarado

San Diego State University

\section{Paul Chavez}

University of California San Diego

Vincent Berardi ( $\nabla$ berardi@chapman.edu )

Chapman University https://orcid.org/0000-0001-9760-6241

\section{Research}

Keywords: Cannabis, Sedentary Behavior, Physical Activity, Accelerometry, Behavioral Epidemiology

Posted Date: June 29th, 2020

DOI: https://doi.org/10.21203/rs.3.rs-38024/v1

License: (c) (1) This work is licensed under a Creative Commons Attribution 4.0 International License. Read Full License 


\section{Abstract}

Background: Prior research examining the relationship between cannabis use, sedentary behavior, and physical activity has generated conflicting findings, potentially due to biases in the self-reported measures used to assess physical activity. This study aimed to more precisely explore the relationship between cannabis use and sedentary behavior/physical activity using objective measures.

Methods: Data were obtained from the 2005-2006 National Health and Nutrition Examination Survey. 2,092 participants (ages 20-59; 48.8\% female) had accelerometer-measured sedentary behavior, light physical activity, and moderate-to-vigorous physical activity. Participants were classified as a current cannabis user if they reported any use over the previous 30 days. Multivariable linear regression estimated minutes engaged in sedentary behavior/physical activity for current versus non-current cannabis users. Logistic regression modeled self-reported moderate-to-vigorous physical activity in relation to current cannabis use.

Results: Fully-adjusted regression models indicated that current cannabis users' objectively-measured sedentary behavior/physical activity did not significantly differ from non-current users. There were no significant associations between self-reported moderate-to-vigorous physical activity and cannabis use.

Conclusions: This study is the first to evaluate the relationship between cannabis use and accelerometermeasured sedentary behavior and physical activity. Such objective measures should be used in other cohorts to replicate our finding that current cannabis use is not significantly associated with sedentary behavior/physical activity in order to fully assess the potential public health impact of recent increases in cannabis use.

\section{Background}

Regular physical activity (PA) is associated with a host of health benefits, such as reduced risks for cardiovascular disease, diabetes, and all-cause mortality, while sedentary behavior (SB; e.g., sitting while watching television (1)) is linked with increased health risks (2-4). However, less than one quarter of U.S. adults aged 18-64 meet federally-recommended PA guidelines (5). This insufficiency likely plays a role in the high prevalence rates of several cardiometabolic conditions, including metabolic syndrome, obesity, cardiovascular disease, and diabetes that the U.S. currently experiences (6-9). This trend in morbidity has coincided with, and possibly been affected by, an increase in cannabis use and a decrease in perceived risk over the past two decades in the U.S. (10). While research has shown that cannabis users have lower odds of metabolic syndrome and other cardiometabolic disease risk factors (11-13), these findings have typically not considered lifestyle factors, which play a significant role in the prevention and management of chronic conditions (14-16). One important lifestyle consideration is physical behavior (which encompasses both SB and PA), whose relationship with cannabis use is not well understood.

Prior research has posited that endogenous cannabinoids (i.e., cannabinoids occurring naturally in the 
consumption of exogenous cannabinoids (i.e., cannabis use), but this mechanism is not fully understood (17). Alternatively, it has been suggested that exogenous cannabinoids have indirect positive effects on health by reducing pain and inflammation, making an individual more likely to engage in PA $(18,19)$. Congruent with these conflicting hypothesized mechanisms for the PA-cannabinoid relationship, previous studies have produced inconsistent findings concerning the association between cannabis use and physical behavior, although they have often focused on different subpopulations. In the U.S., more than $80 \%$ of participants in states with full legal access to cannabis reported concurrent cannabis use with exercise (20), while an examination of eight years of data from the National Health and Nutrition Examination Survey (NHANES) suggested that cannabis users have lower odds of engaging in selfreported PA compared to non-current users (21). A study of self-reported PA among adolescents from 21 low- and middle-income countries found current cannabis users had lower odds of meeting the World Health Organization's PA recommendations for adolescents (22). Additionally, African American and Puerto Rican young adults who used cannabis were found to have a reduced probability of being obese (23), but cannabis use was also associated with low levels of sport and exercise in young Swiss men (24) and excessive television watching (a metric of SB) in Dutch adolescents (25). A study of Slovenian adolescents found no relationship between frequency of cannabis use and either SB or PA (26).

To date, studies examining the relationship between cannabis use and physical behavior have relied on self-report measures via questionnaires, which are subject to recall (27) and social desirability (28) biases that have the potential to generate inaccuracies. Specific to PA, it may be easier to report single-instance behaviors (e.g., "Have you gone on a run in the past 7 days?") versus recalling the amount of time engaged in various intensities of PA. Moreover, regular cannabis use is known to impair memory recall $(29,30)$, possibly reducing accurate self-reported measures of physical behavior among cannabis users. As an alternative, accelerometers (e.g., Fitbit) have become a common tool for objectively assessing physical behavior. A systematic review found weak-to-moderate correlations between accelerometry measures and PA questionnaires $(0.08 \leq r \leq 0.58$; (31)). Another study displayed even weaker correlations between accelerometry measures and light PA $(0.01 \leq r \leq 0.06)$ and moderate correlations for accelerometry and SB $(0.28 \leq r \leq 0.31$; (32)). These inconsistencies raise concerns over the accuracy of using questionnaires to assess the relationship between cannabis use and physical behavior.

The current study aimed to account for potential shortcomings in self-report assessments within cannabis and physical behavior studies by incorporating objective measures of SB, light PA, and moderate-to-vigorous PA (MVPA) into analyses. We analyzed NHANES accelerometer and questionnaire data to investigate differential levels of SB and PA among current cannabis users and non-current users. Our aim was to clarify the relationship between cannabis use and physical behavior to inform the evaluation of changes in physical behavior patterns as a potential public health impact of cannabis use.

\section{Methods}

\section{Sample Description}


Data were obtained from NHANES, a program of studies by the National Center for Health Statistics which assesses the health and nutritional status of the U.S. population through questionnaires, interviews, physical examinations, and laboratory tests (33). NHANES uses a stratified, multistage probability sampling design to attain a nationally representative sample of the non-institutionalized U.S. population. The sampling procedure begins with selecting primary sampling units (counties) which are then divided into segments (city blocks). A sample of households within each segment is randomly drawn and individuals within those households are randomly selected. Only the 2005-2006 NHANES cycle has concurrent accelerometer and cannabis use measures, so analyses were restricted to this time period. The sample was limited to participants aged 20-59 years $(n=3,409)$, since only respondents in this age range were given drug and alcohol use questionnaires. Participants were excluded if they did not have one or more adherent accelerometer wear days, defined as having at least 10 hours of wear time $(n=652$; (34)); did not complete the Drug Use Questionnaire $(n=124)$; had incomplete cannabis use questions $(n=$ 303); reported concurrent use of heroin, cocaine, or methamphetamines $(n=30)$; or self-reported or tested positive for pregnancy via urine test $(n=208)$. The final analytic sample contained 2,092 participants.

\section{Measures of Cannabis Use}

Using responses from the Drug Use Questionnaire (35), cannabis use was determined by responses to the following questions: "Have you ever, even once, used marijuana or hashish?" (yes, no). Individuals who responded "yes" were directed to the following question: "During the past 30 days, on how many days did you use marijuana or hashish?". Current cannabis users were defined as those who used cannabis ${ }^{3} 1$ day in the past 30 days. All other participants were classified as non-current users.

\section{Accelerometer measures of physical activity and sedentary behavior}

Participants were requested to wear an Actigraph 7164 over their right hip for 7 days and to remove the device only for showering, swimming, and when in bed. The accelerometer data was processed via a computer script released by the National Cancer Institute, the full details of which are published elsewhere (36). Briefly, using the most common protocol for adults, accelerometer non-wear was characterized by 60 consecutive minutes with zero movement allowing for up to 2 minutes of movement below 50 counts per minute (cpm; (34)). As is commonly defined, an adherent day was designated as having at least 10 hours of wear time (34). Common acceleration cutpoints were then used to categorize different behaviors: minutes with less than $100 \mathrm{cpm}$ were classified as sedentary, minutes between 100 and $1951 \mathrm{cpm}$ were classified as light PA, and minutes above $1951 \mathrm{cpm}$ were considered MVPA $(37,38)$. The physical behavior metrics used in all analyses were computed as the average number of minutes in sedentary time, light PA, and MVPA over all adherent days.

\section{Measures of self-reported physical activity}

Participants self-reported their levels of PA through the Physical Activity Questionnaire (35). Engagement in MVPA was determined by the following questions: "Over the past 30 days, did you do moderate 
breathing or heart rate?" (yes, no); "Over the past 30 days, did you do any vigorous activities for at least 10 minutes that caused heavy sweating, or large increases in breathing or heart rate?" (yes, no).

Responses to these questions were combined into one binary yes/no variable; if a respondent replied "yes" to one or both questions, they were categorized as having self-reported MVPA engagement. This method of measurement was chosen to replicate a previous study that used NHANES data to examine the cannabis-PA relationship (21). Self-reported light PA and SB were not assessed due to lack of appropriately corresponding questions in 2005-2006 NHANES.

\section{Covariates}

Sociodemographic covariates included age, gender, race/ethnicity, income-to-poverty ratio, and education. Health-related covariates included body mass index (BMI), cigarette smoking status, and alcohol use. All covariates were obtained through self-report with the exception of $\mathrm{BMI}$, which was measured by trained examiners. Age was reported in years and gender was indicated as male or female. Race/ethnicity was categorized as Non-Hispanic White, Non-Hispanic Black, Hispanic (inclusive of Mexican American and Other Hispanic), or Other (inclusive of Asian and multi-racial); non-Hispanic White was the reference level. Income-to-poverty ratio was calculated by dividing family income by the poverty threshold. Education was indicated as one of five categories: less than $9^{\text {th }}$ grade, $9^{\text {th }}-11^{\text {th }}$ grade, high school graduate/GED, some college/AA degree, or college graduate and above (less than $9^{\text {th }}$ grade was the reference level). Body mass index was calculated based on height and weight measurements. Cigarette smoking status was determined by the following questions: "Have you smoked at least 100 cigarettes in your entire life?" (yes, no) and "Do you now smoke cigarettes?" (every day, some days, not at all). Current cigarette smokers were classified as those who answered "yes" to smoking at least 100 cigarettes in their lifetime and now smoke "every day" or "some days." Alcohol use was defined by the average number of days per week participants drank and was assessed using the following questions: "In your entire life, have you had at least 12 drinks of any type of alcoholic beverage?" (yes, no); "In the past 12 months, how often did you drink any type of alcoholic beverage? How many days per week, per month, or per year did you drink?" (responses recorded from 0-365). Responses were converted to days per week as applicable. Participants who have not had at least 12 alcoholic drinks in their lifetime or responded with "0" to frequency of drinking in the past 12 months were recorded as drinking an average of 0 days per week.

\section{Statistical analyses}

All statistical analyses were performed in R Version 3.6.1 (39) using the survey package (40), which accounts for NHANES sample weights, strata, and primary sampling units to make results more generalizable to the U.S. population. To determine statistical significance, a was set to 0.05 .

Means and frequencies of covariates were calculated for the total sample and separately by cannabis use categories. Differences between these groups were tested using $t$-tests for continuous variables and $c^{2}$ tests for categorical variables. 
To account for differences in physical behavior measurements resulting from differences in the duration of wear time, SB, light PA, and MVPA were adjusted for accelerometer wear time via the commonly used $(36,41)$ residuals method $(42)$. Linear regression models assessed associations of cannabis use with SB, light PA, and MVPA as separate outcome variables using the following successively adjusted regression models: Model 1 (unadjusted), Model 2 (adjusted for age and gender), and Model 3 (adjusted for age, gender, ethnicity, income-to-poverty ratio, education, body mass index, cigarette smoking status, and alcohol use). Models 1 and 2 contained 2,092 observations while Model 3 contained 2,022 observations due to missing income-to-poverty ratio, $\mathrm{BMI}$, or alcohol use data. To facilitate interpretation, regression results are reported as marginal means (40).

To assess potential effect modification, interaction terms for cannabis use and (a) age, (b) gender, and (c) cigarette smoking status were added to Model 3. Previous research has documented age and gender differences in SB time (43) and associations between cigarette smoking and cannabis dependence (44). Marginal means of SB, light PA, and MVPA were estimated for current and non-current cannabis users and differences were computed and reported separately for each level of the potential modifiers in Model 3. Age was dichotomized into younger or older than the median sample age (40 years) for the reporting of marginal means. Statistical significance of the between-level differences was obtained from the $p$-value of the interaction coefficients in the regression model.

To replicate a previous study (21), logistic regression models were calculated with self-reported MVPA as a binary outcome. Three logistic models were created using the same covariates and sample sizes as the linear accelerometry models (without interaction terms).

\section{Sensitivity Analysis}

The non-interaction regression analyses were re-analyzed for a subsample of participants that had a minimum of four adherent accelerometer wear days $(n=1,618)$, an eligibility criterion thought to produce physical behavior estimates that more accurately represent usual weekly behavior patterns. Results were substantively similar, so only those derived from the full sample are detailed below.

\section{Results}

\section{Descriptive statistics}

Current cannabis users differed significantly from non-current users on all included sociodemographic and health-related covariates (Table 1). Current cannabis users were younger (mean age 34.2 vs. 41.1 years), more likely to be White ( $54.2 \%$ vs. $46.4 \%)$, male ( $71.5 \%$ vs. $48.5 \%)$, have higher rates of some college/AA degree (39.4\% vs. 33.4\%), have lower BMI (mean 26.5 vs. 28), and have lower income-topoverty ratio (mean 2.8 vs. 3.3). A majority of cannabis users were current cigarette smokers $(51 \%)$ and they drank alcoholic beverages an average of 2 days per week. 
In the unadjusted and age/gender-adjusted models, cannabis users engaged in significantly less SB than non-current users $(p<0.05)$. Following adjustment for all covariates, there was no statistical difference in SB between current and non-current cannabis users (470.7 $\mathrm{min} /$ day vs. $481.7 \mathrm{~min} /$ day, $p=$ 0.38; Table 2).

Similarly, when controlling for all covariates, current cannabis users engaged in a similar amount of PA as non-current users (light PA: $366.4 \mathrm{~min} /$ day vs. $349.7 \mathrm{~min} /$ day, $p=0.19 ;$ MVPA: $29.1 \mathrm{~min} /$ day vs. $27.3 \mathrm{~min} /$ day, $p=0.43$ ).

\section{Interaction effects}

Associations between cannabis use and physical behavior did not significantly differ by age, gender, or cigarette smoking status ( $p>0.11$; Table 3$)$.

\section{Self-reported MVPA}

Current cannabis users and non-current users had a similar prevalence of self-reported MVPA (current users: $70.3 \%$; non-current users: $67.8 \%, p=0.90$ ) and were no more or less likely to report engaging in MVPA than non-current users in any of the three logistic regression models (Table 4).

\section{Discussion}

To our knowledge, this is the first study to use objective accelerometry measures to assess the relationship between cannabis use and physical behavior in a population-based sample of U.S. adults. The results suggest that current cannabis users and non-current users did not significantly differ in their levels of SB and PA. Consistent with the objective measures, current cannabis users and non-current users did not significantly differ in their self-reported MVPA in both the fully-adjusted and age/genderadjusted models. Both objective and subjective measures illustrated the same null association between MVPA and current cannabis use.

Our results can be compared to the analysis of 2007-2014 NHANES data by Vidot et al. (21), who used self-reported PA assessments to find lower odds of engaging in MVPA for current cannabis users compared to non-current users (21). In contrast, our results show no significant differences in accelerometer-measured or self-reported MVPA (with self-reported MVPA measured identically to their study) between cannabis users and non-current users when controlling for all covariates. Vidot et al. (21) examined data from a longer time period than the current study, yielding nearly 6.5 times as many cannabis users for analyses, which may contribute to the discrepancy between results. Furthermore, given the well-documented inconsistencies between objectively and subjectively reported PA, it is possible that self-report biases contribute to the Vidot et al. (21) findings. In our unadjusted models, current cannabis users engaged in significantly more objectively measured MVPA than non-current users, while selfreporting MVPA at similar rates. This might indicate that objective versus subjective measures lead to 
differences when assessing the relationship between cannabis use and physical behavior, but the sample size was not large enough to detect differences in the fully-adjusted model.

Our findings do not support the mainstream perception of cannabis users as living sedentary lifestyles (20). As cannabis's legal status and risk perception changes (10), cannabis users have sought to challenge this stereotype, as demonstrated by recent events such as the 420 Games held in Los Angeles, California, which featured a $5 \mathrm{k}$ run (45). While the relationship between cannabis use and physical behavior has yet to be definitively established, it is possible that public perception of cannabis users has shifted, especially after the federal legalization of Cannabidiol (CBD) in 2018. This prospect should be explored in future research.

Age was negatively correlated with MVPA and positively correlated with SB in our sample, which is expected since the aging process contributes physiological barriers to engaging in high intensity PA (46). There was a consistent trend of larger differences in physical behavior observed for older participants than younger participants by current cannabis use status (see Table 3), though this interaction was not statistically significant $(p>0.11)$. The absence of significance may be due to the small number of cannabis users in our sample $(n=249)$ and even fewer older cannabis users $(70 \%$ of cannabis users were below age 40), thus limiting the stratified analyses. Though not conclusive, this pattern suggests that cannabis use may have greater implications for PA in an older population. If true, a possible explanation is that cannabis is being used for exercise-induced pain recovery, since PA brings about pain and muscle soreness (47) and a decreased pain threshold and muscle hypersensitivity have been documented among older adults (48). Certain cannabinoids, particularly CBD, have been shown to positively impact inflammation so older adults may use cannabis to manage PA-related discomfort (19). Future research should explicitly assess possible age differences in physical behavior by cannabis use status.

A considerable limitation to this study is the cross-sectional design, which does not allow the causality between cannabis use and levels of physical behavior to be determined. Second, accelerometer data were only available for the 2005-2006 NHANES, so the number of cannabis users in the sample was not large enough to stratify into current versus past versus never use categories, as previous studies have done (21, 22). While the legal and social context surrounding cannabis use have likely changed since the data used in this study was generated, this work establishes the need to incorporate objective measures into future studies and the results serve as a baseline with which this future work can be compared. Third, the NHANES Drug Use Questionnaire did not distinguish between strains of cannabis, which have varying levels of Tetrahydrocannabinol, the psychoactive component in cannabis, and are known to produce differing experiences for users $(49,50)$. These differences may lead to distinct relationships with physical behavior. Furthermore, participants did not report their reasons for cannabis use, which may impact the cannabis-physical behavior relationship. Lastly, accelerometers were not waterproof and thus were unable to capture any water-based PA, such as swimming.

Despite its limitations, this study was novel in its use of objective accelerometer data within a standardized. nationallv representative ponulation-based survey. The objective accelerometry measures Loading [MathJax]/jax/output/CommonHTML/jax.js 
used in this study allowed physical behavior to be described with increased accuracy. Future studies using this approach should investigate more nuanced features of the cannabis-physical behavior relationship, including the precise timing and duration of SB and PA events.

\section{Conclusions}

Current cannabis use was not significantly associated with time engaged in accelerometer-measured SB, light PA, or MVPA in a nationally representative sample of U.S. adults. Results derived from self-reported MVPA aligned with the non-significant results produced by accelerometer measures. Age, gender, and cigarette smoking status did not moderate the association between cannabis use and physical behavior. Findings add to the cannabis and physical behavior literature by incorporating objective accelerometer measures. Further understanding of the association between cannabis use and health behaviors is essential to fully assessing the public health concerns associated with cannabis use.

\section{Abbreviations}

PA

Physical Activity; SB:Sedentary Behavior; NHANES:National Health and Nutrition Examination Survey; MVPA:Moderate-to-Vigorous Physical Activity; cpm:Counts per Minute; BMI:Body Mass Index; SD:Standard Deviation; GED:General Education Development; AA:Associates of Arts.

\section{Declarations}

\section{Ethics approval and consent to participate}

Not applicable.

\section{Consent for publication}

Not applicable.

\section{Availability of data and materials}

The datasets used and/or analyzed during the current study are available in the Centers for Disease Control and Prevention/National Center for Health Statistics repository.

https://wwwn.cdc.gov/nchs/nhanes/Default.aspx

\section{Competing interests}

The authors declare they have no competing interests.

\section{Funding}




\section{Authors' contributions}

LO was involved in all aspects of the project, including the performance of statistical analyses and the drafting and revising of the entire manuscript. JB was involved in all aspects of the project, including conceptualizing the study, reviewing statistical analyses, and drafting the manuscript. CA conducted the literature review and preliminary statistical analyses and aided with drafting the manuscript. PC conducted the literature review and aided with drafting the manuscript. VB was involved in all aspects of the project, including conceptualizing the study, overseeing statistical analyses, and drafting the manuscript.

\section{Acknowledgements}

Not applicable.

\section{References}

1. Tremblay MS, Aubert S, Barnes JD, Saunders TJ, Carson V, Latimer-Cheung AE, et al. Sedentary Behavior Research Network (SBRN) - Terminology Consensus Project process and outcome. Int J Behav Nutr Phys Act. 2017;14(1):1-17.

2. Powell KE, King AC, Buchner DM, Campbell WW, DiPietro L, Erickson KI, et al. The scientific foundation for the physical activity guidelines for Americans, 2nd edition. J Phys Act Heal. 2019;16(1):1-11.

3. Ekelund U, Tarp J, Steene-Johannessen J, Hansen BH, Jefferis B, Fagerland MW, et al. Dose-response associations between accelerometry measured physical activity and sedentary time and all cause mortality: systematic review and harmonised meta-analysis. Bmj. 2019;|4570.

4. LaCroix AZ, Bellettiere J, Rillamas-Sun E, Di C, Evenson KR, Lewis CE, et al. Association of Light Physical Activity Measured by Accelerometry and Incidence of Coronary Heart Disease and Cardiovascular Disease in Older Women. JAMA Netw open. 2019;2(3):e190419.

5. Blackwell D, Clarke T. State variation in meeting the 2008 federal guidelines for both aerobic and muscle-strengthening activities through leisure-time physical activity among adults aged 18-64: United States, 2010-2015. Natl Health Stat Report. 2018;(112).

6. Marcotte-Chenard A, Deshayes TA, Ghachem, Ahmed, Brochu M. Prevalence of the metabolic syndrome between 1999 and 2014 in the United States adult population and the impact of the 20072008 recession: an NHANES study. Appl Physiol Nutr Metab. 2019;44(8):861-9.

7. Stokes A, Ni Y, Preston SH. Prevalence and Trends in Lifetime Obesity in the U.S., 1988-2014. Am J Prev Med. 2017;53(5):567-75.

8. Benjamin EJ, Virani SS, Callaway CW, Chamberlain AM, Chang AR, Cheng S, et al. Heart disease and stroke statistics - 2018 update: A report from the American Heart Association. Circulation. 2018;137(12):E67-492. 
9. Stokes A, Preston SH. The contribution of rising adiposity to the increasing prevalence of diabetes in the United States. Prev Med (Baltim). 2017;101:91-5.

10. 10.1016/j.ypmed.2017.07.008

Carliner H, Brown QL, Sarvet AL, Hasin DS. Cannabis use, attitudes, and legal status in the U.S.: A review. Prev Med (Baltim) [Internet]. 2017;104:13-23. Available from:

https://doi.org/10.1016/j.ypmed.2017.07.008.

11. Penner EA, Buettner $H$, Mittleman MA. The impact of marijuana use on glucose, insulin, and insulin resistance among US adults. Am J Med. 2013;126(7):583-9.

12. Vidot DC, Prado G, Hlaing WWM, Florez HJ, Arheart KL, Messiah SE. Metabolic Syndrome Among Marijuana Users in the United States: An Analysis of National Health and Nutrition Examination Survey Data. Am J Med. 2016;129(2):173-9.

13. Meier MH, Pardini D, Beardslee J, Matthews KA. Associations Between Cannabis Use and Cardiometabolic Risk Factors: A Longitudinal Study of Men. Psychosom Med. 2019;81(3):281-8.

14. Milani RV, Lavie CJ. Health care 2020: Reengineering health care delivery to combat chronic disease. Am J Med. 2015;128(4):337-43.

15. Danaei G, Ding EL, Mozaffarian D, Taylor B, Rehm J, Murray CJL, et al. The preventable causes of death in the United States: Comparative risk assessment of dietary, lifestyle, and metabolic risk factors. PLoS Med. 2009;6(4).

16. Edwards MK, Loprinzi PD. High Amounts of Sitting, Low Cardiorespiratory Fitness, and Low Physical Activity Levels: 3 Key Ingredients in the Recipe for Influencing Metabolic Syndrome Prevalence. Am J Heal Promot. 2018;32(3):587-94.

17. Dietrich A, McDaniel WF. Endocannabinoids and exercise. Br J Sports Med. 2004;38(5):536-41.

18. Gillman AS, Hutchison KE, Bryan AD. Cannabis and Exercise Science: A Commentary on Existing Studies and Suggestions for Future Directions. Sport Med. 2015;45(10):1357-63.

19. Kozela E, Juknat A, Kaushansky N, Rimmerman N, Ben-Nun A, Vogel Z. Cannabinoids decrease the Th17 inflammatory autoimmune phenotype. J Neuroimmune Pharmacol. 2013;8(5):1265-76.

20. 10.3389/fpubh.2019.00099/full

YorkWilliams SL, Gust CJ, Mueller R, Bidwell LC, Hutchison KE, Gillman AS, et al. The New Runner's High? Examining Relationships Between Cannabis Use and Exercise Behavior in States With Legalized Cannabis. Front Public Heal [Internet]. 2019;7(April):1-7. Available from: https://www.frontiersin.org/article/10.3389/fpubh.2019.00099/full.

21. 10.1016/j.drugalcdep.2017.05.004

Vidot DC, Bispo JB, Hlaing WWM, Prado G, Messiah SE. Moderate and vigorous physical activity patterns among marijuana users: Results from the 2007-2014 National Health and Nutrition Examination Surveys. Drug Alcohol Depend [Internet]. 2017;178(December 2016):43-8. Available from: http://dx.doi.org/10.1016/j.drugalcdep.2017.05.004.

22. 10.1016/j.drugalcdep.2019.107584

Loading [MathJax]/jax/output/CommonHTML/jax.js

Page $11 / 17$ 
Ashdown-Franks G, Sabiston CM, Vancampfort D, Smith L, Firth J, Solmi M, et al. Cannabis use and physical activity among 89,777 adolescents aged 12-15 years from 21 low- and middle-income countries. Drug Alcohol Depend [Internet]. 2019;205(August):107584. Available from: https://doi.org/10.1016/j.drugalcdep.2019.107584.

23. Brook JS, Lee JY, Finch SJ, Balka EB, Brook DW. Physical factors, personal characteristics, and substance use: Associations with obesity. Subst Abus. 2013;34(3):273-6.

24. 10.1016/j.ypmed.2014.03.022

Henchoz Y, Dupuis M, Deline S, Studer J, Baggio S, N'Goran AA, et al. Associations of physical activity and sport and exercise with at-risk substance use in young men: A longitudinal study. Prev Med (Baltim) [Internet]. 2014;64:27-31. Available from: http://dx.doi.org/10.1016/j.ypmed.2014.03.022.

25. Busch V, Manders LA, De Leeuw JRJ. Screen time associated with health behaviors and outcomes in adolescents. Am J Health Behav. 2013;37(6):819-30.

26. Lesjak V, Stanojević-Jerković O. Physical Activity, Sedentary Behavior and Substance use Among Adolescents in Slovenian Urban Area / Telesna Aktivnost, Oblike Sedečega Vedenja In Uživanje Psihoaktivnih Snovi Med Mladostniki V Slovenskem Urbanem Okolju. Slov J Public Heal. 2015;54(3):168-74.

27. Coughlin SS. Recall bias in epidemiologic studies. J Clin Epidemiol. 1990;43(1):87-91.

28. Krumpal I. Determinants of social desirability bias in sensitive surveys: A literature review. Qual Quant. 2013;47(4):2025-47.

29. Battisti RA, Roodenrys S, Johnstone SJ, Respondek C, Hermens DF, Solowij N. Chronic use of cannabis and poor neural efficiency in verbal memory ability. Psychopharmacology. 2010;209(4):319-30.

30. Ranganathan M, Souza DCD. The acute effects of cannabinoids on memory in humans: a review. 2006.

31. 10.1186/s12889-016-3172-0

Skender S, Ose J, Chang-Claude J, Paskow M, Brühmann B, Siegel EM, et al. Accelerometry and physical activity questionnaires - A systematic review. BMC Public Health [Internet]. 2016;16(1):1-10. Available from: http://dx.doi.org/10.1186/s12889-016-3172-0.

32. LaMonte MJ, Lee I-M, Rillamas-Sun E, Bellettiere J, Evenson KR, Buchner DM, et al. Comparison of Questionnaire and Device Measures of Physical Activity and Sedentary Behavior in a Multi-Ethnic Cohort of Older Women. J Meas Phys Behav. 2019;2(2):82-93.

33. Centers for Disease Control and Prevention. National Health and Nutrition Examination Survey Data. Hyattsville: U.S. Department of Health and Human Services, Centers for Disease Control and Prevention. Hyattsville, MD; 2005.

34. Migueles JH, Cadenas-Sanchez C, Ekelund U, Delisle Nyström C, Mora-Gonzalez J, Löf M, et al. Accelerometer Data Collection and Processing Criteria to Assess Physical Activity and Other 
35. Centers for Disease Control and Prevention. National Health and Nutrition Examination Survey Questionnaire (or Examination Protocol, or Laboratory Protocol). Hyattsville, MD; 2005.

36. Healy GN, Matthews CE, Dunstan DW, Winkler EAH, Owen N. Sedentary time and cardio-metabolic biomarkers in US adults: NHANES 200306. Eur Heart J. 2011;32(5):590-7.

37. Freedson PS, Melanson E, Sirard J. Calibration of the Computer Science and Applications, Inc. accelerometer. Med Sci Sport Exerc [Internet]. 1998;30(5):777-81. Available from: https://www.ncbi.nlm.nih.gov/pubmed/9588623.

38. Matthews CE, Chen KY, Freedson PS, Buchowski MS, Beech BM, Pate RR, et al. Amount of time spent in sedentary behaviors in the United States, 2003-2004. Am J Epidemiol. 2008;167(7):875-81.

39. Team RC. R: A language and environment for statistical computing [Internet]. Vienna, Austria: R Foundation for Statistical Computing; 2019. Available from: https://www.r-project.org/.

40. Lumley T. survey: analysis of complex survey samples. R package version 3.35-1. 2019.

41. Qi Q, Strizich G, Merchant G, Sotres-Alvarez D, Buelna C, Castañeda SF, et al. Objectively measured sedentary time and cardiometabolic biomarkers in US Hispanic/Latino adults: The Hispanic Community Health Study/Study of Latinos (HCHS/SOL). Circulation. 2015;132(16):1560-9.

42. Willett W, Stampfer MJ. Total energy intake: Implications for epidemiologic analyses. Am J Epidemiol [Internet]. 1986;124(1):17-27. Available from: https://www.ncbi.nlm.nih.gov/pubmed/3521261.

43. Bellettiere J, Carlson JA, Rosenberg D, Singhania A, Natarajan L, Berardi V, et al. Gender and age differences in hourly and daily patterns of sedentary time in older adults living in retirement communities. PLoS One. 2015;10(8).

44. 10.1016/j.drugalcdep.2015.01.004

Hindocha C, Shaban NDC, Freeman TP, Das RK, Gale G, Schafer G, et al. Associations between cigarette smoking and cannabis dependence: A longitudinal study of young cannabis users in the United Kingdom. Drug Alcohol Depend [Internet]. 2015;148:165-71. Available from: http://dx.doi.org/10.1016/j.drugalcdep.2015.01.004.

45. Fox H. One Toke Over the (Finish) Line: This Weekend's 420 Games Combat the Lazy Stoner Stereotype with a Festival of Fitness. The Argonaut [Internet]. 2018; Available from: https://argonautnews.com/one-toke-over-the-finish-line/.

46. National Institute on Drug Abuse; National Institutes of Health; U.S. Department of Health and Human Services. Physical Activity Guidelines for Americans, 2nd edition. Washington, DC: U.S.; 2018.

47. Dannecker EA, Koltyn KF. Pain during and within hours after exercise in healthy adults. Sport Med. 2014;44(7):921-42.

48. Vecchiet L. Muscle pain and aging. J Musculoskelet Pain. 2002;10(1-2):5-22.

49. Hillig KW, Mahlberg PG. A chemotaxonomic analysis of cannabinoid variation in Cannabis (Cannabaceae). Am J Bot. 2004;91(6):966-75.

50. Pearce DD, Mitsouras K, Irizarry KJ. Discriminating the effects of Cannabis sativa and Cannabis indica: A web survey of medical cannabis users. J Altern Complement Med. 2014;20(10):787-91. 


\section{Tables}

\section{Table 1}

Descriptive Statistics of Adults with Completed Drug Questionnaire and Accelerometer Use, National Health and Nutrition Examination Survey 2005-2006.

\begin{tabular}{|c|c|c|c|c|}
\hline Overall Sample & Current Users & Non-Current Users & $p$ & \\
\hline$N=2,092$ & $n=249$ & $n=1,843$ & & \\
\hline Age, mean $(S D)^{a}$ & $40.3(11.1)$ & $34.2(10.8)$ & $41.1(10.9)$ & $<0.001$ \\
\hline Gender, $n(\%)$ & $<0.001$ & & & \\
\hline Male & $1072(51.2)$ & 178 (71.5) & $894(48.5)$ & \\
\hline Female & $1020(48.8)$ & $71(28.5)$ & $949(51.5)$ & \\
\hline Race/Ethnicity, $n(\%)$ & $<0.01$ & & & \\
\hline Non-Hispanic White & $990(47.3)$ & $135(54.2)$ & $855(46.4)$ & \\
\hline Hispanic & $511(24.4)$ & $33(13.3)$ & $478(25.9)$ & \\
\hline Non-Hispanic Black & $501(24)$ & $71(28.5)$ & $430(23.3)$ & \\
\hline Other/Multi-Racial & $90(4.3)$ & $10(4.0)$ & $80(4.3)$ & \\
\hline Income-to-Poverty Ratio, mean (SD) ${ }^{a}$ & $3.3(1.6)$ & $2.8(1.6)$ & $3.3(1.6)$ & $<0.002$ \\
\hline Education Level, $n(\%)$ & $<0.002$ & & & \\
\hline$<9^{\text {th }}$ Grade & $161(7.7)$ & $8(3.2)$ & $153(8.3)$ & \\
\hline $9^{\text {th }}-11^{\text {th }}$ Grade & $281(13.4)$ & $52(20.9)$ & $229(12.4)$ & \\
\hline High School & $480(22.9)$ & $65(26.1)$ & $415(22.5)$ & \\
\hline \multicolumn{5}{|l|}{ Graduate/GED ${ }^{b}$} \\
\hline Some College/ $A A^{c}$ Degree & $714(34.1)$ & $98(39.4)$ & $616(33.4)$ & \\
\hline College Graduate or above & $456(21.8)$ & $26(10.4)$ & $430(22.3)$ & \\
\hline Body Mass Index, mean (SD) ${ }^{a}$ & $28.7(7)$ & $26.5(5.3)$ & $28(7.1)$ & $<0.001$ \\
\hline Current Cigarette Smoker, $n(\%)$ & $449(21.5)$ & $126(51)$ & $323(17.5)$ & $<0.002$ \\
\hline Alcohol Use, mean (SD) ${ }^{a}$ & $1.1(1.8)$ & $2.1(2.2)$ & $1.0(1.7)$ & $<0.001$ \\
\hline
\end{tabular}


${ }^{b}$ GED: General Education Development; high school equivalency

${ }^{\mathrm{c}} \mathrm{AA}$ : Associates of Arts

\section{Table 2}

Time Spent Engaged in Physical Behavior by Cannabis Use Category.

\begin{tabular}{|c|c|c|c|}
\hline Current Users & Non-Current Users & $p$ & \\
\hline$n=249$ & $n=1,843$ & & \\
\hline Mean $(\min / \text { day })^{\mathrm{a}}(\mathrm{SE})^{\mathrm{b}}$ & Mean $(\min / \text { day })^{\mathrm{a}}(\mathrm{SE})^{\mathrm{b}}$ & & \\
\hline \multicolumn{4}{|l|}{ Sedentary Behavior ${ }^{\mathrm{C}}$} \\
\hline Model 1 & $458.1(6.7)$ & $482.9(4)$ & $<0.005$ \\
\hline Model 2 & $462.7(6.8)$ & $482.3(4.1)$ & $<0.02$ \\
\hline Model 3 & $470.7(8.6)$ & $481.7(4.8)$ & $<0.38$ \\
\hline \multicolumn{4}{|l|}{ Light Physical Activityc } \\
\hline Model 1 & $373.2(10.1)$ & $348.3(4.5)$ & $<0.04$ \\
\hline Model 2 & $373.6(9.4)$ & $348.3(4.4)$ & $<0.03$ \\
\hline Model 3 & $366.4(8.0)$ & $349.7(4.9)$ & $<0.19$ \\
\hline \multicolumn{4}{|c|}{ Moderate-to-Vigorous Physical Activity ${ }^{c}$} \\
\hline Model 1 & $33.0(2.1)$ & $26.5(0.8)$ & $<0.003$ \\
\hline Model 2 & $28.6(2.0)$ & $27.1(0.7)$ & $<0.44$ \\
\hline Model 3 & $29.1(2.1)$ & $27.3(0.7)$ & $<0.43$ \\
\hline
\end{tabular}

a All estimates are weighted due to the survey design.

b SE: Standard Error

${ }^{\mathrm{c}}$ Activity variables were adjusted for accelerometer wear time.

Model 1: Unadjusted model $(N=2,092)$

Model 2: Adjusted for age and gender $(N=2,092)$

Model 3: Adjusted for age, gender, race/ethnicity, education, income-to-poverty ratio, body mass index, cigarette smoker status, and alcohol use $(N=2,022)$

Loading [MathJax]/jax/output/CommonHTML/jax.js 


\section{Table 3}

Multivariable-Adjusted Differences Between Current Cannabis Users Versus Non-Current Users in Time Spent in Physical Behavior Stratified by Age, Gender, and Current Cigarette Smoking Status.

\begin{tabular}{|c|c|c|c|c|c|c|c|c|c|}
\hline \multirow{2}{*}{$\begin{array}{c}\mathrm{Age}^{\mathrm{a}} \\
40\end{array}$} & \multirow[b]{2}{*}{$\begin{array}{l}> \\
40\end{array}$} & \multicolumn{2}{|c|}{ Gender $^{\mathrm{a}}$} & \multicolumn{3}{|c|}{$\begin{array}{l}\text { Current Cigarette } \\
\text { Smoker }^{a}\end{array}$} & & \multirow[b]{3}{*}{$p^{\mathrm{c}}$} & \\
\hline & & Male & Female & Yes & No & \multirow{2}{*}{\multicolumn{2}{|c|}{$\begin{array}{l}\text { Difference in } \\
\text { Mean } \\
(\min / \text { day })^{b}\end{array}$}} & & \\
\hline $\begin{array}{l}\text { Difference in Mean } \\
(\min / \text { day })^{b}\end{array}$ & & $p^{c}$ & \multicolumn{2}{|c|}{$\begin{array}{l}\text { Difference in } \\
\text { Mean }(\mathrm{min} / \text { day })^{\mathrm{b}}\end{array}$} & \multirow{2}{*}{$\begin{array}{l}p^{c} \\
-32.1\end{array}$} & & & & \\
\hline Sedentary Behavior & -2.4 & -36.5 & 0.11 & -3.1 & & 0.21 & -12.4 & -14.1 & 0.98 \\
\hline $\begin{array}{l}\text { Light Physical } \\
\text { Activity }\end{array}$ & 8.3 & 31.4 & 0.11 & 22.1 & 3.7 & 0.43 & 17.4 & 13.9 & 0.91 \\
\hline $\begin{array}{l}\text { Moderate-to- } \\
\text { Vigorous Physical } \\
\text { Activity }\end{array}$ & 0.8 & 6.5 & 0.14 & 0.4 & 5.0 & 0.45 & 2.7 & 2.6 & 0.91 \\
\hline
\end{tabular}

${ }^{a}$ Models adjusted for all original covariates except for the stratification variable.

${ }^{b}$ Difference in means calculated by subtracting non-current user estimates from current cannabis user estimates. All estimates are weighted due to the survey design.

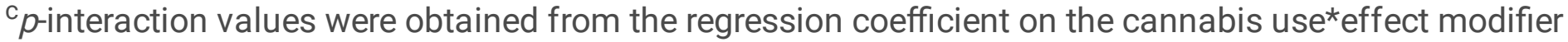
interaction term.

\section{Table 4}

Adjusted Odds of Self-Reported Moderate-to-Vigorous Physical Activity by Cannabis Use Category. 


\begin{tabular}{|lll|}
\hline $\begin{array}{l}\text { Current Users } \\
n=249\end{array}$ & \\
\hline $\begin{array}{l}\text { Reference Group = Non-Current Users } \\
\text { OR }(95 \% \mathrm{Cl})\end{array}$ & & \\
\hline Self-Reported Moderate-to-Vigorous Physical Activity & & \\
\hline Model 1 & $1.00(0.91-1.10)$ & 0.93 \\
\hline Model 2 & $0.98(0.90-1.08)$ & 0.72 \\
\hline Model 3 & $1.05(0.98-1.12)$ & 0.44 \\
\hline
\end{tabular}

Model 1: Unadjusted model $(N=2,092)$

Model 2: Adjusted for age and gender $(N=2,092)$

Model 3: Adjusted for age, gender, race/ethnicity, education, income-to-poverty ratio, body mass index, cigarette smoker status, and alcohol use $(N=2,022)$

\section{Supplementary Files}

This is a list of supplementary files associated with this preprint. Click to download.

- CoverLetter.docx 